\title{
NAD(P)H Oxidase in Non-Phagocytic Cells
}

\author{
A. Görlach
}

\section{Introduction}

The importance of reactive oxygen intermediates (ROI) is evident from the vast literature describing the involvement of free radicals in the pathogenesis of various disorders including neurological (Alzheimer's disease, Parkinson's disease), viral human immunodeficiency virus (HIV) and acquired immunodeficiency syndrome (AIDS), and degenerative (atherosclerosis, cancer, cataract) diseases.

The generation of ROI is an activity normally associated with phagocytes. As part of the body's host defense system these cells are able, when stimulated by various agents including bacterial toxins, to generate large amounts of superoxide in the respiratory burst in order to kill invading microorganisms. Over the past ten years it has become increasingly apparent that non-phagocytic cells also share the capacity to generate oxygen radicals. Such activity has been detected in a wide variety of different cells including endothelial cells, vascular smooth muscle cells, mesangial cells, fibroblasts, oocytes, spermatozoa, Leydig cells, various tumor cells, thyroid cells, B-lymphocytes, adipocytes, platelets, chondrocytes and osteoblasts. Since the capacity to generate ROI is widespread, the risk-benefit relation for these potentially hazardous molecules becomes a matter of interest. Whereas the controlled generation of these highly reactive molecules may serve an important second messenger role in many different cell types, their uncontrolled production may contribute to the etiology of pathological conditions through the initiation and propagation of peroxidative damage. Therefore the identification of sources of ROI in non-phagocytic cells is of considerable interest.

Recently, evidence has accumulated that nicotinamide adenine dinucleotide (phosphate) $[\mathrm{NAD}(\mathrm{P}) \mathrm{H}]$ oxidases might also be present in non-phagocytic cells. However, the molecular identity and function of these systems are only beginning to be elucidated. This article will summarize current knowledge about the presence of $\mathrm{NAD}(\mathrm{P}) \mathrm{H}$ oxidases in non-phagocytic cells.

\section{NADPH Oxidase in Phagocytes}

NADPH oxidase is a highly regulated membrane-bound enzyme complex which was initially found in phagocytes. As the key enzyme for the respiratory burst, it catalyzes $\mathrm{O}_{2}^{-}$production according to the following reaction [1]: 
Although $\mathrm{O}_{2}^{-}$is a free radical, it is unreactive towards many organic molecules and not an oxidant at neutral $\mathrm{pH}$ [2]. It is highly solute in water and is not expected to be transported through membranes or to penetrate into hydrophobic regions of cells and peroxide lipids. However, it readily, either spontaneously or catalyzed by superoxide dismutase (SOD), dismutes to hydrogen peroxide $\left(\mathrm{H}_{2} \mathrm{O}_{2}\right)$ an oxidant, germicide and cytotoxic agent. This ROI is stable and carries no charge, allowing it to cross membranes and to travel freely to its targets. It readily participates in oneelectron processes with metal ions such as the Fenton reaction, thereby generating highly reactive hydroxyl radicals. Other toxic weapons generated in phagocytes from $\mathrm{O}_{2}^{-}$include oxidized halogens and singlet oxygen [3].

In resting cells NADPH oxidase is dormant and the protein components are segregated into cytoplasmic and plasma membrane compartments [1]. The enzyme can be activated by receptor-dependent stimuli such as complement fragment $\mathrm{C} 5 \mathrm{a}$, the chemotactic tripeptide N-formyl-methionyl-leucyl-phenylalanine (fMLP) and immune complexes, for example via the G-protein activated phospholipase $\mathrm{C}$ pathway, finally stimulating protein kinase $\mathrm{C}$ and phospholipase $\mathrm{D}$. Receptor-independent stimuli include long-chain unsaturated fatty acids and phorbol-myristate-acetate (PMA) $[4,5]$.

On stimulation, the cytosolic proteins $\mathrm{p} 47, \mathrm{p} 67$ and $\mathrm{p} 40$ form a complex and translocate to the plasma membrane, where they associate with a membrane-bound flavocytochrome composed of two subunits, p22 and gp91 (Fig. 1) [4]. The low molecular weight guanosine tri-phosphate (GTP)-binding protein, rac, changes from an inactive guanosine diphosphate (GDP)-bound to an active GTP-bound form and translocates separately to the plasma membrane, where it probably modulates the function of one or more NADPH oxidase proteins [6].The role of additional factors such as $\mathrm{p} 40$, which also translocates to the membrane, and the membrane bound rap1A, known as tumor suppressor gene, in the activation process are not

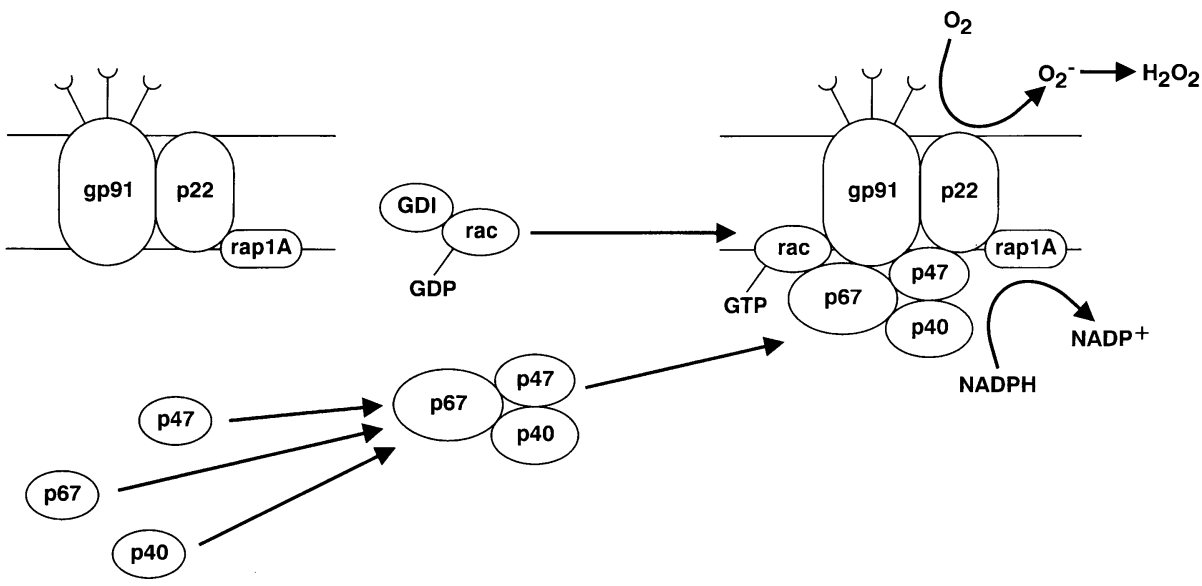

Fig.1. Assembly of the NADPH oxidase components in phagocytes. Under resting conditions membrane-bound components are separated from cytosolic factors. On activation, the cytosolic components assemble and translocate to the membrane where they associate with cytochrome b558. Independently, rac also translocates to the membrane 
fully understood. Recently p40 has been suggested to down-modulate NADPH oxidase function [7].

The unusual low midpoint potentials of the two hemes in the cytochrome, $-225 \mathrm{mV}$ and $-265 \mathrm{mV}$, facilitate the electron flow from $\mathrm{NAD}(\mathrm{P}) \mathrm{H}$ via flavin adenine dinucleotide (FAD) to the cytochrome and molecular oxygen [4]. Both, NADPH $\left(\mathrm{K}_{\mathrm{m}} \sim 30 \mu \mathrm{M}\right)$ and $\mathrm{NADH}\left(\mathrm{K}_{\mathrm{m}} \sim 200 \mu \mathrm{M}\right)$, can be used as reducing agents. The $\mathrm{K}_{\mathrm{m}}$ for oxygen, the other oxidase substrate, was determined around $10 \mu \mathrm{M}$ (below $1 \% \mathrm{O}_{2}$ in water), suggesting that the enzyme can produce $\mathrm{O}_{2}^{-}$even under hypoxic conditions such as in infected tissue. In contrast to other cytochromes, cytochrome b558 binds carbon monoxide $(\mathrm{CO})$ with low affinity $\left(\mathrm{K}_{\mathrm{m}} \sim 1.4 \mathrm{mM}\right)$ and cannot be re-oxidized by respiratory chain inhibitors like cyanide or rotenone [3]. Protons arising from NADPH oxidation cross the membrane via a $\mathrm{Cd}^{2+} / \mathrm{Zn}^{2+}$ sensitive proton channel probably located in the gp91 subunit of the cytochrome [8]. They act as compensating ions as they accompany the electrons that were moved electrogenically to reduce oxygen to superoxide. The dismutation of $\mathrm{O}_{2}^{-}$then consumes $\mathrm{H}^{+}$to produce $\mathrm{H}_{2} \mathrm{O}_{2}$.

The importance of NADPH oxidase in host defense is made evident by a rare inherited disorder, chronic granulomatous disease (CGD), in which mutations in any of four components of this enzyme lead to a failure to generate $\mathrm{O}_{2}^{-}$, rendering the patients highly susceptible to life threatening microbial infections [5]. The complementary deoxyribonucleic acids (cDNAs) for all components have been cloned and sequenced, and the genes encoding these proteins have been localized and characterized. Recently, at least one highly homologous pseudogene has been identified for the $\mathrm{p} 47$ gene [9]. The transcript for $\mathrm{p} 22$ is constitutively present in a variety of tissues, whereas gp91 as well as the cytosolic factors p40, p47 and p67 are considered to be predominantly expressed in the white cell line $[5,7]$. Promoter elements in the gp91 and p47 genes have been identified as being responsible for this line confinement $[10,11]$.

\section{NAD(P)H Oxidase in Non-Phagocytic Cells}

The potential to generate low levels of superoxide has been described in several non-phagocytic cell types. Whereas some cell types spontaneously generate ROI, other cell types require, similar to phagocytes, activating stimuli such as cytokines, phorbol esters or calcium ionophores. The amount of ROI generated by nonphagocytic cells typically reaches around $1 \%-10 \%$ of the ROI levels produced in the respiratory burst by activated neutrophils [3]. Low levels of ROI are non-toxic and can lead to modulation of intracellular signaling, gene expression, cell proliferation and cell death [2]. The proliferation of several cell types, including fibroblasts and T-lymphocytes, can be stimulated by small amounts of superoxide [3]. Thus, the cellular functions of free radicals can be roughly summarized in five categories:

(1) cytokine, growth factor, and hormone action and secretion;

(2) ion transport;

(3) transcription;

(4) neuromodulation;

(5) apoptosis (for review see [12]). 
Numerous signaling pathways are known to be affected by ROI including arachidonate metabolism, protein kinases and transcription factors such as nuclear factorkappa B (NF- $\mathrm{kB}$ ) activator protein (AP-1), p53 and hypoxia inducible factor-1 (HIF-1). ROI are involved in the induction of immediate early response genes such as $c$-fos, $c-j u n, c-m y c$ and $e g r-1$. Recently it has been suggested that they participate in the activation of the ras pathway [13]. Given these multiple actions in various tissues, the identification of potential sources of ROI in cellular systems is of major importance.

Many oxygen radical producing systems are known to modulate the cellular redox state including xanthine oxidase, lipoxygenases, cyclooxygenases, as well as the respiratory chain [12]. The identification of ROI generating systems relies mainly on the use of more or less specific inhibitors of the various enzymes. Based on the decrease of superoxide production by the application of diphenylene iodonium (DPI), an inhibitor of NADPH oxidase, but not by inhibitors of other radical generating enzymes (see above), the presence of $\mathrm{NAD}(\mathrm{P}) \mathrm{H}$ oxidase was suggested in various cell types including spermatozoa, pneumocytes, thyroid cells, and tumor cells $[3,14]$. However, DPI has been shown to be a rather non-specific inhibitor of flavoprotein containing enzymes, among them nitric oxide synthase (NOS), and no specific NADPH oxidase inhibitor is available at the moment [15]. The presence of an $\mathrm{NAD}(\mathrm{P}) \mathrm{H}$ oxidase was also postulated when $\mathrm{NADPH}$ and/or $\mathrm{NADH}$ were required to generate superoxide. A number of cell types showed, in contrast to the phagocyte NADPH oxidase, higher affinities for NADH than for NADPH. Therefore it appears appropriate to suggest that in many non-phagocytic cell types NADPH/ $\mathrm{NADH}$ oxidases exist, and some of them might represent isoforms of the phagocyte enzyme.

However, only a limited number of studies so far provide direct evidence for the presence of non-phagocytic $\mathrm{NAD}(\mathrm{P}) \mathrm{H}$ oxidase. In a number of cells types a heme protein exhibiting the characteristic features of cytochrome b558, such as an absorption maximum at $558 \mathrm{~nm}$, a very low midpoint potential, and insensitivity to cyanide, could be identified. However, non-phagocytic cells contained substantially lower amounts of cytochrome b558 than phagocytes. Further proof for the presence of $\mathrm{NAD}(\mathrm{P}) \mathrm{H}$ oxidase in non-phagocytic cells has been provided by the detection of NADPH oxidase components at the mRNA and/or protein level in several cell types (Table 1) which are described in more detail in the section below.

\section{Oxygen Sensing Cells}

Under hypoxic conditions specific adaptive responses are induced in order to sustain and improve oxygen availability to the tissues. Specific chemoreceptive organs such as the carotid body actively regulate ventilation and circulation. In the kidney, the expression of the glycoprotein hormone erythropoietin is dramatically enhanced, to stimulate erythropoiesis and thereby improve oxygen transport capacity to the tissues. Moreover, many, if not all, other cell types are able to adapt their activity according to variations in oxygen availability, for example, by the modulation of channel activities and/or gene expression. Whereas oxygen dependent transcription factors such as HIF-1 have been identified in various cell types, the oxygen sensor 
Table 1. NAD $(\mathrm{P}) \mathrm{H}$ oxidase in non-phagocytic cells

\begin{tabular}{|c|c|c|c|c|}
\hline Method of detection & $\begin{array}{l}\text { Spectro- } \\
\text { photo- } \\
\text { metry }\end{array}$ & $\begin{array}{l}\text { mRNA level } \\
\text { (Northern, } \\
\text { RT-PCR) }\end{array}$ & $\begin{array}{l}\text { Protein level } \\
\text { (Western, Immuno- } \\
\text { fluorescence) }\end{array}$ & $\begin{array}{l}\text { Cloning } \\
\text { (cDNA) }\end{array}$ \\
\hline \multicolumn{5}{|l|}{ Cell type } \\
\hline Hepatoma HepG2 & + & $\mathrm{p} 22$ & p22,p47,p67, gp91 & \\
\hline Endothelial cells & + & p22,p47,p67,gp91 & $\mathrm{p} 47, \mathrm{p} 67$ & \\
\hline Smooth muscle cells & + & $\mathrm{p} 22$ & gp91 & $\mathrm{p} 22$ \\
\hline Mesangial cells & + & $\mathrm{p} 22, \mathrm{p} 47, \mathrm{p} 67$ & p22,gp91 & \\
\hline Fibroblasts & + & $\mathrm{p} 22, \mathrm{p} 47, \mathrm{p} 67$ & $\mathrm{p} 22, \mathrm{gp} 91$ & \\
\hline Chondrocytes & & $\mathrm{p} 22, \mathrm{p} 40, \mathrm{P} 47$ & p67 & \\
\hline Carotid body, type I cells & + & & p22,p47, p67,gp91 & \\
\hline Neuroepithelial bodies & + & p22,gp91 & p22, p47, p67, gp91 & \\
\hline SIF cells ${ }^{\mathrm{a}}$ & & & $\mathrm{p} 22$ & \\
\hline
\end{tabular}

${ }^{a}$ Small intensely fluorescent cells

This table summarizes NADPH oxidase components identified in non-phagocytic cells. By spectrophotometry, a low potential cy tochrome b558 component was detected which could not be reoxidized by cyanide. No spectroscopic data were available from chondrocytes and SIF cells.

remains obscure. A heme protein has been suggested to act as an oxygen sensor by changing the conformational state according to the amount of oxygen available (for review see $[16,17])$.

Based on spectrophotometric studies in erythropoietin-producing hepatoma cells a b-type heme protein similar to the cytochrome b558 was suggested to be involved in oxygen sensing [18]. This b-cytochrome was reducible by hypoxia but not by cyanide, and it had a low affinity to CO. The expression of all four NADPH oxidase components was demonstrated by either Western blot analysis or immunofluorescence [18]. These cells produced ROI depending on the oxygen availability. The addition of $\mathrm{H}_{2} \mathrm{O}_{2}$ resulted in a substantial decrease in hypoxic erythropoietin production whereas the presence of scavenging systems stimulated erythropoietin production already under normoxic conditions, suggesting that the decrease in ROI putatively generated by an $\mathrm{NAD}(\mathrm{P}) \mathrm{H}$ oxidase might allow the up-regulation of erythropoietin in hypoxia [19].

Similar studies were performed in chemoreceptive organs known to be crucially involved in oxygen sensing in the body. The addition of $\mathrm{H}_{2} \mathrm{O}_{2}$ inhibited the hypoxic nerve discharge in the carotid body [20]. The spectrophotometric detection of cytochrome b558 together with the identification of four NADPH oxidase components by immunofluorescence in hypoxia-responsive type I cells in the carotid body suggested again the involvement of $\mathrm{NAD}(\mathrm{P}) \mathrm{H}$ oxidase in oxygen sensing [21].

In pulmonary neuroepithelial bodies representing airway chemoreceptive organs in the lung, all $\mathrm{NAD}(\mathrm{P}) \mathrm{H}$ oxidase components were identified in close vicinity to oxygen sensitive $\mathrm{K}^{+}$channels in the membrane. Since the activity of these channels could be modulated by $\mathrm{H}_{2} \mathrm{O}_{2}$ it was suggested that an $\mathrm{NAD}(\mathrm{P}) \mathrm{H}$ oxidase might be involved in oxygen-dependent regulation of channel activity in neuroepithelial bodies [22, 23]. Moreover, p22 expression and $\mathrm{H}_{2} \mathrm{O}_{2}$ production have also been 
demonstrated in small intensely fluorescent cells (SIF), hypoxia-sensitive paraganglionic structures found throughout the body [24], indicating that $\mathrm{NAD}(\mathrm{P}) \mathrm{H}$ oxidase might play a specific role in oxygen sensitive cells. However, the molecular identity of these components remains to be clarified. In CGD patients no defect in oxygen sensing has become apparent, indicating that either multiple overlapping oxygen sensing systems are present, or that $\mathrm{NAD}(\mathrm{P}) \mathrm{H}$ oxidase isoforms exist in oxygen sensing cells.

\section{Vascular System}

The potential to generate free radicals has long been recognized in the vascular system. In pig coronary arteries and rabbit aortas low basal values have been measured. Indirect evidence using DPI to inhibit ROI production suggests that an enzyme similar to NADPH oxidase is also present in vascular cells [3].

In calf small pulmonary arteries the presence of a low potential cytochrome b558 was demonstrated spectrophotometrically. The detection of gp91 expression by Western blot analysis suggested the presence of $\mathrm{NAD}(\mathrm{P}) \mathrm{H}$ oxidase. In contrast to other studies superoxide production increased from 1.4 to $73 \mathrm{nmol} \mathrm{O}_{2}^{-} / \mathrm{min} / \mathrm{mg}$ protein in these cells under hypoxic conditions. Since DPI could inhibit hypoxic superoxide production as well as hypoxic vasoconstriction, it was suggested that $\mathrm{NAD}(\mathrm{P}) \mathrm{H}$ oxidase might play a role in pulmonary hypoxic vasoconstriction [25].

Approximately $24 \%$ of ROI release has been accounted for as being derived from endothelial cells [26]. Cultured endothelial cells respond to a diverse range of stimuli including cytokines, bradykinin, calcium ionophores, phorbol esters, and cyclic strain with the generation of low levels of ROI (for review see [26, 27]). Hypoxia/reoxygenation stress is able to increase ROI production in endothelial cells whereas under hypoxic conditions superoxide production is strictly dependent on the $\mathrm{PO}_{2}$ $[28,29]$. Excess production of ROI has been related to the pathogenesis of atherosclerosis. Under pathological conditions such as hypercholesterolemia, hypertension and diabetes, ROI appear to participate in the deregulation of vascular tone [26]. Superoxide has also been suggested to be identical to the endothelial derived contracting factor in analogy to endothelial derived relaxing factor (EDRF) which has been identified as nitric oxide (NO) [3].

Human umbilical venous endothelial cells were able to generate seven times more superoxide when using NADH instead of NADPH. However, iodonium diphenyl (IDP), a flavoprotein inhibitor, impaired the response three times more efficiently when NADPH was used as substrate. The presence of $\mathrm{NAD}(\mathrm{P}) \mathrm{H}$ oxidase in human umbilical venous endothelial cells was supported by the identification of all four components (p22, gp91, p47, p67) of the NADPH oxidase by reverse transcriptase polymerase chain reaction (RT-PCR) using oligonucleotides derived from phagocyte sequences [27]. Partial sequence analysis revealed a high homology to the neutrophil sequences. Furthermore p47 and p67 expression could be detected by immunofluorescence and Western blot analysis. Although this study was the first to suggest gp91 transcripts in non-phagocytic cells, no evidence for a low-potential cytochrome b558 could be detected spectrophotometrically. It was speculated that a post-transcriptional block as has been observed in B-lymphocytes might also 
impair the effective translation of gp91 in endothelial cells. Alternatively, heme availability might restrict the formation of a stable cytochrome b558. Additional studies will have to analyze in more detail the structure and function of endothelial $\mathrm{NAD}(\mathrm{P}) \mathrm{H}$ oxidase.

Whereas ROI have been shown to stimulate proliferation of vascular smooth muscle cells (VSMC) [3], the generation of ROI by smooth muscle cells apparently contributes significantly to the overall ROI production by different types of blood vessels [26]. A variety of stimuli can activate the generation of ROI in smooth muscle cells, such as growth factors, insulin and fatty acids. For example, the glycosphingolipid lactosylceramide stimulated the generation of superoxide in membrane fractions from human aortic smooth muscle cells in the presence of NADPH but not NADH. Since DPI could inhibit the radical generation as well as the proliferation of these cells, the presence of an $\mathrm{NAD}(\mathrm{P}) \mathrm{H}$ oxidase activated by this glycosphingolipid was suggested as mediating the proliferative stimulus [30]. In rat VSMC, oxidase activity could be measured using NADPH and $\mathrm{NADH}$ as substrates, leading to basal levels of activity of $3.23 \mathrm{nmol} \mathrm{O} \mathrm{O}_{2}^{-} / \mathrm{min} / \mathrm{mg}$ protein and $16.76 \mathrm{nmol} \mathrm{O} \mathrm{O}_{2}^{-} / \mathrm{min} / \mathrm{mg}$ protein respectively. DPI was more effective in inhibiting NADPH than NADH oxidase activity. The NAD $(\mathrm{P}) \mathrm{H}$ oxidase activity was localized in the membrane fraction and could be stimulated approximately four-fold by angiotensin II (ATII) [31]. Subsequent studies proved this finding in vivo and showed that ATII could up-regulate p22 mRNA levels. Cloning of rat p22 from a rat VSMC library revealed a high homology to the neutrophil component. Using an anti-sense approach, the ability to generate $\mathrm{O}_{2}^{-}$was found to be critically dependent on p22. Cytochrome b558 was demonstrated spectrophotometrically in cells overexpressing p22, but could not be detected in cells transfected with an anti-sense construct [33]. However, no evidence for the presence of gp91 could be found in this study, suggesting that a structurally distinct form of this protein is present in these cells. As ATII mediates hypertrophy of smooth muscle cells which can lead to hypertension, $\mathrm{NAD}(\mathrm{P}) \mathrm{H}$ oxidase activity has been related to ATII mediated hypertension [32]. These studies provide the first evidence that $\mathrm{NAD}(\mathrm{P}) \mathrm{H}$ oxidase components are functional in non-phagocytic cells.

\section{Kidney}

Human kidney glomerular mesangial cells (HMC) produce ROI when stimulated with tumor necrosis factor (TNF)- $\alpha$, interleukin-1 $\alpha$ (IL-1 $\alpha$ ), or IL-1 $\beta$ as well as with calcium ionophores. ROI generation has been related to the pathogenesis of glomerular injury [34]. By RT-PCR, transcripts for p22 were detected in resting cells, whereas p47 and p67 transcripts were only found in HMC treated with IL- $1 \beta$. Sequence analysis of the PCR fragments revealed approximately $98 \%$ homology with the neutrophil sequence. Immunodetection studies showed the presence of $\mathrm{p} 22, \mathrm{p} 47$, and p67. Although by spectroscopy a low potential cytochrome b558 in HMC membranes could be demonstrated in a concentration of $60 \mathrm{pmol} / \mathrm{mg} \mathrm{mem}$ brane protein, gp91 could not be identified by RT-PCR or immunoblotting. In contrast, the presence of gp91 was demonstrated immunohistochemically in rat visceral glomerular epithelial cells with passive Heymann nephritis [35] indicating that $\mathrm{NAD}(\mathrm{P}) \mathrm{H}$ oxidase components or their homologs might be induced during inflam- 
mation. Alternatively, isoforms of this enzyme may exist containing a differently composed cytochrome b558. Recently, in rabbit proximal tubular epithelial cells of the kidney, indirect evidence, provided by the inhibitory action of DPI on $\mathrm{O}_{2}^{-}$production, indicated that arachidonic acid activates an $\mathrm{NAD}(\mathrm{P}) \mathrm{H}$ oxidase to release superoxide which stimulates $c$-jun $\mathrm{N}$-terminal kinase [36].

\section{Other Cell Types}

In fibroblasts a low potential cytochrome b558 was detected spectrophotometrically in a concentration of about $10 \mathrm{pmol} / \mathrm{mg}$ protein [37]. ROI release could be observed in fibroblasts stimulated with various cytokines, calcium ionophores or PMA. However, a cell-cycle dependent, very low basal ROI production was also observed, consistent with the finding that ROI are involved in proliferation of fibroblasts [37]. Transcripts were found for p22, p47 and p67, using RT-PCR but not for gp91. The presence of $\mathrm{p} 47$ protein could also be demonstrated by Western blot analysis [38]. However, fibroblasts from healthy donors and gp91 deficient CGD patients did not differ in their ability to produce superoxide, indicating that the fibroblast cytochrome is genetically distinct from the neutrophil cytochrome b558 [37].

In porcine articular chondrocytes the calcium ionophore ionomycin stimulated superoxide production which could be inhibited by IDP [39]. The presence of transcripts for p22, p47 and p40 was shown by RT-PCR. Furthermore the expression of p67 could be demonstrated by Western blot analysis. The ability to generate ROI spontaneously or after stimulation with various cytokines has been noted previously [40]. The local production of ROI in chondrocytes may be important for the terminal differentiation of chondrocytes in the hypertrophic and calcified zones of the growth plates. The excess generation of ROI might play a role in the degradation of matrix in arthritis.

Evidence for an $\mathrm{NAD}(\mathrm{P}) \mathrm{H}$ oxidase expressing $\mathrm{p} 22$, gp91 and $\mathrm{p} 47$ as demonstrated by immunofluorescence has also been shown in osteoclasts [41]. As these cells derive from common myelo-monocytic precursors it can be speculated that they might contain a genetically identical $\mathrm{NAD}(\mathrm{P}) \mathrm{H}$ oxidase form. However, there are no reports to date demonstrating that osteoclasts derived from CGD patients contain non-functional $\mathrm{NAD}(\mathrm{P}) \mathrm{H}$ oxidase due to mutations in the enzyme subunits.

\section{Conclusion}

Many cell types have the potential to generate ROI. In contrast to the cytotoxic activity observed in phagocytes, non-phagocytic cells generate low rates of ROI which might serve as signaling molecules. NADPH oxidase plays an important role in the generation of ROI in phagocytes, but has also been identified in non-phagocytic cells. However, the substrate requirements for the phagocyte and non-phagocyte enzymes are different in that, in the latter, $\mathrm{NADH}$ is used more efficiently than NADPH. Although high sequence homologies appear to exist between the phagocyte and non-phagocytic enzyme components, the molecular and genetic identity of these proteins in non-phagocytic cells remains to be clarified. First reports in vascular 
smooth muscle cells have demonstrated that $\mathrm{NAD}(\mathrm{P}) \mathrm{H}$ oxidase components are functional and critically involved in the cell's potential to generate ROI. The identification of ROI generating systems in non-phagocytic cells will provide important insights into the role of oxygen generating systems in cellular signaling and might allow new therapeutic tools to be developed for various disease processes ranging from inflammatory disorders to ischemic diseases and cancer.

Acknowledgements. I thank C. Gasser for the art work, and Drs. C. Bauer and M. Gassmann for support.

\section{References}

1. Jones OTG (1994) The regulation of superoxide production by the NADPH oxidase of neutrophils and other mammalian cells. Bioessays 16:919-922

2. Khan AU, Wilson $T$ (1995) Reactive oxygen species as cellular messengers. Chem Biol 2:437-445

3. Cross AR, Jones OTG (1991) Enzymatic mechanisms of superoxide production. Biochem Biophys Acta 1057:281-298

4. Leusen JHW, Verhoeven AJ, Roos D (1996) Interactions between the components of the human NADPH oxidase: Intrigues in the phox family. J Lab Clin Med 128:461-476

5. Curnutte JT (1993) Chronic granulomatous disease: the solving of a clinical riddle. Clin Immunol Immunopath 67:S2-S15

6. DeLeo FR, Quinn M (1996) Assembly of the phagocyte NADPH oxidase: molecular interaction of oxidase proteins. J Leukoc Biol 60:677-691

7. Saythyamoorthy M, deMendez I, Adams AG, Leto TL (1997) p40phox down-regulates NADPH oxidase activity through interactions with its SH3 domain. J Biol Chem 272:9141-9146

8. Henderson LM, Thomas S, Banting G, Chappell JB (1997) The arachidonate-activable, NADPH oxidase-associated $\mathrm{H}^{+}$channel is contained within the multi-membrane-spanning $\mathrm{N}$-terminal region of gp91-phox. Biochem J 325:701-705

9. Görlach A, Lee PL, Roester J, et al (1997) A p47-phox Pseudogene carries the most common mutation causing p47-phox-deficient chronic granulomatous disease. J Clin Invest 100:1907-1918

10. Lien LL, Lee Y Orkin SH (1997) Regulation of the myeloid-cell-expressed human gp91phox gene as studied by transfer of yeast artificial chromosome clones into embryonic stem cells: suppression of a variegated cellular pattern of expression requires a full complement of distant cis elements. Mol Cell Biol 17:2279-2290

11. Li SL, Valente AJ, Zhao SJ, Clark RA (1997) Pu.1 is essential for $\mathrm{p} 47$ (phox) promoter activity in myeloid cells. J Biol Chem 272:17802-17809

12. Lander HM (1997) An essential role for free radicals and derived species in signal transduction. FASEB J $11: 118-124$

13. Irani K, Xia Y, Zweier JL, et al (1997) Mitogenic signaling mediated by oxidants in Ras transformed fibroblasts. Science 275:1649-1652

14. van Klaveren RJ, Roelant C, Boogaerts M, Demedts M, Nemery B (1997) Involvement of an $\mathrm{NAD}(\mathrm{P}) \mathrm{H}$ oxidase-like enzyme in superoxide anion and hydrogen peroxide generation by rat type II cells. Thorax 52:465-471

15. O'Donnell VB, Tew DG, Jones OTG, England PJ (1993) Studies on the inhibitory mechanism of iodonium compounds with specific reference to neutrophil NADPH oxidase. Biochem J 290:41-49

16. Bunn HF, Poyton RO (1996) Oxygen sensing and molecular adaptation to hypoxia. Physiol Rev $76: 839-885$

17. Acker $H$ (1994) Mechanisms and meaning of cellular oxygen sensing in the organism. Resp Physiol 95:1-10

18. Görlach A, Holtermann G, Jelkmann W, et al (1993) Photometric characteristics of haem proteins in erythropoietin-producing hepatoma cells (HepG2). Biochem J 290:771-776

19. Fandrey J, Frede S, Jelkmann W (1994) Role of hydrogen peroxide in hypoxia-induced erythropoietin production. Biochem J 303:507-510 
20. Acker H, Bölling B, Delpiano MA, Dufau E, Görlach A, Holtermann G (1992) The meaning of $\mathrm{H}_{2} \mathrm{O}_{2}$ generation in carotid body cells for $\mathrm{pO}_{2}$ chemoreception. J Auton Nerv Syst 41:41-52

21. Kummer W, Acker H (1995) Immunohistochemical detection of four subunits of neutrophil NAD(P)H oxidase in type I cells of carotid body. J Appl Physiol 78:1904-1909

22. Wang D, Youngson C, Wong V, et al (1996) NADPH-oxidase and a hydrogen peroxide-sensitive $\mathrm{K}^{+}$channel may function as an oxygen sensor complex in airway chemoreceptors and small lung cell carcinoma cell lines. Proc Natl Acad Sci USA 93:13182-13187

23. Youngson C, Nurse C, Yeger $\mathrm{H}$, et al (1997) Immunocytochemical localization of $\mathrm{O}_{2}$-sensing proteins (NADPH oxidase) in chemoreceptor cells. Microsc Res Tech 37:101-106

24. Kummer W, Acker H (1997) Cytochrome b558 and hydrogen peroxide production in small intensely fluorescent cells of sympathetic ganglia. Histochem Cell Biol 197:151-158

25. Marshall C, Mamary AJ, Verhoeven AJ, Marshall BE (1996) Pulmonary artery NADPH-oxidase is activated in hypoxic pulmonary vasoconstriction. Am J Resp Cell Mol Biol 15:633-644

26. Brandes RP, Barton M, Philippens KHM, Schweitzer G, Mügge A (1997) Endothelial-derived superoxide anions in pig coronary arteries: evidence from lucigene chemiluminescence and histochemical techniques. J Physiol 500:331-342

27. Jones SA, O'Donnell V, Wood JD, Broughton JP, Hughes EJ, Jones OTG (1996) Expression of phagocyte NADPH oxidase components in human endothelial cells. Am J Physiol 271: H1626-H1634

28. Zulueta JJ, Yu FS, Hertig IA, Thannickal VJ, Hassoun PM (1995) Release of hydrogen peroxide in response to hypoxia-reoxygenation: role of an $\mathrm{NAD}(\mathrm{P}) \mathrm{H}$ oxidase-like enzyme in endothelial cell plasma membrane. Am J Resp Cell Mol Biol 12:41-49

29. Kinnula VK, Mirza Z, Cerapo JD, Whorton AR (1993) Modulation of hydrogen peroxide release from vascular endothelial cells by oxygen. Am J Resp Cell Mol Biol 9:603-609

30. Bhunia AK, Han H, Snowden A, Chatterjee S (1997) Redox-regulated signaling by lactosylceramide in the proliferation of human aortic smooth muscle cells. J Biol Chem 272:15642-15649

31. Griendling KK, Minieri CA, Ollerenshaw JD, Alexander RW (1994) Angiotensin II stimulates NADH and NADPH oxidase activity in cultured vascular smooth muscle cells. Circ Res 74: $1141-1148$

32. Rajagopalan S, Kurz S, Münzel T, et al (1996) Angiotensin II-mediated hypertension in the rat increases vascular superoxide production via membrane NADH/NADPH oxidase activation. J Clin Invest 97: 1916-1923

33. Ushio-Fukai M, Mazia-Zafari A, Fukui T, Ishizaka N, Griendling KK (1996) p22phox is a critical component of the superoxide-generating NADH/NADPH oxidase system and regulates angiotensin II-induced hypertrophy in vascular smooth muscle cells. J Biol Chem 271:23317-23321

34. Jones SA, Hancock JT, Jones OTG, Neubauer A, Topley N (1995) The expression of NADPH oxidase components in human glomerular mesangial cells: detection of protein and mRNA for p47phox, p67phox, and p22phox. J Am Soc Nephrol 5:1483-1491

35. Neale TJ, Ullrich R, Ojha P, Poczewski H, Verhoeven AJ, Kerjaschki D (1993) Reactive oxygen species and neutrophil respiratory burst cytochrome b558 are produced by kidney glomerular cells in passive Heymann nephritis. Proc Natl Acad Sci USA 90:3645-3649

36. Cui XL, Douglas JG (1997) Arachidonic acid activates c-jun N-terminal kinase through NADPH oxidase in rabbit proximal tubular epithelial cells. Proc Natl Acad Sci USA 94:3771-3776

37. Meier B, Jesaitis AJ, Emmendoerfer A, Roesler J, Quinn MT (1993) The cytochrome b-558 molecules involved in the fibrobalst and polymorphonuclear leucocyte superoxide-generating NADPH oxidase systems are structurally and genetically distinct. Biochem J 289:481-486

38. Jones SA, Wood JD, Coffey MJ, Jones OTG (1994) The functional expression of p47-phox and p67-phox may contribute to the generation of superoxide by an NADPH oxidase-like system in human fibroblasts. FEBS Lett 355:178-182

39. Hiran TS, Moulton PJ, Hancock JT (1997) Detection of superoxide and NADPH oxidase in porcine articular chondrocytes. Free Rad Biol Med 23:736-743

40. Rathakrishanan C, Tiku K, Raghavan A, Tiku MT (1992) Release of oxygen radicals by articular chondrocytes: a study of luminol-dependent chemiluminescence and hydrogen peroxide secretion. J Bone Min Res 7:1139-1148

41. Steinbeck MJ, Appel WH, Verhoeven AJ, Karnovsky MJ (1994) NADPH-oxidase expression and in situ production of superoxide by osteoclasts actively resorbing bone. J Cell Biol 126: $765-772$ 